\title{
Conf-920607--8
}

Mons

GI-A- -20851

AFKO 1992

\section{A CRYOCONDENSATION PUMP FOR THE DIII-D ADVANCED DIVERTOR PROGRAM}

\author{
by' \\ J.P. SMITH, C. BAXI, E. REIS, \\ and $L$. SEVIER
}

MARCH 1992

\section{GENERAL ATOMICS}




\section{DISCLAIMER}

This report was prepared as an account of work sponsored by an agency of the United States Government. Neither the United States Government nor any agency thereof, nor any of their employees, makes any warranty, express or implied, or assumes any legal liability or responsibility for the accurecy, completeness, or usefulneas of any information, apparatus, product, or process disclosed, or represents that its use would not infringe privately owned rights. Reference herein to any apecific commercial product, procens, or service by trade name, trademark, manufacturer, or otherwise, does not necessarily constitute or imply its endorsement, recommendation, or favoring by the United States Government or any agency thereof. The views and opinions of authors expreased herein do not necessarily state or reflect those of the United States Government or any agency thereof. 
GA-A20851

\title{
A CRYOCONDENSATION PUMP FOR THE DIII-D ADVANCED DIVERTOR PROGRAM
}

\author{
by \\ J.P. SMITH, C. BAXI, E. REIS, \\ and L. SEVIER
}

This is a preprint of a paper to be presented at the 10th Topical Meeting on the Technology of Fusion Energy, June 7-11, 1992, Boston, Massachusetts, and to be printed in the Proceedings.

Work supported by

U.S. Department of Energy

Contract No. DE-AC03-89ER51114

GENERAL ATOMICS PROJECT 3466

MARCH 1992

\section{GENERAL ATOMIES




\title{
A CRYOCONDENSATION PUMP FOR THE DIII-D ADVANCED DIVERTOR PROGRAM
}

\author{
J.P. Smith, C. BAXI, E. Reis, AND L. SeVier \\ General Atomics \\ P.O. Box 85608 \\ San Diego, California 92186-9784
}

\section{ABSTRACT}

A cryocondensation pump was designed for the baftle chamber of General Atomics DIII-D tokamak and will be installed in the fall of 1992 . The purpose of the pump is to study plasma density control by pumping of the divertor. The pump is toroidally continuous, approximately $10 \mathrm{~m}$ long and located in the lower outer corner of the vacuum chamber of the machine. It consists of a $1 \mathrm{~m}^{2}$ liquid belium-cooled surface surrounded by a liquid nitrogen-cooled shield to limit the heat load on the helium-cooled surface. The liquid nitrogen-cooled surface is surrounded by a radiation/ particle shield to prevent energetic particles from impacting and releasing condensed water molecules. A thermal enhancement couting was applied to the nitrogen shell to lower the maximum temperature of the shell. The costing is non-continuous to keep the toroidal electrical resistance high. The whole pump is supported off the water-cooled vacuure vessel wall. Supports for the pump were designed to accommodate the thermal differences between the $4 \mathrm{~K}$ belium surface, the $77 \mathrm{~K}$ nitrogen shells, and the $300 \mathrm{~K}$ vacuum vessel supporting the pump and to provide a low heat leak structural support. Disruption loading on the pump was analyzed and a inite element structural analysis of the pump was completed.

A testing program was completed to evaluate costing techniques to enhance heat transfer and emissivity of the various surfaces. Fabrication tests were perforned to determine the best method of attaching the liquid nitrogen flow tubes to their shield surfaces and to determine the best alternative to fabricating the differ. ent shells of the pump. A prototype sector of the pump was built to verify fabrication and assembly techniques.

\section{INTRODUCTION}

General Atomics has performed fusion energy research for more than 30 years and has designed, built, and now operntes DIII-D, a moderate-sized tokamak for the U.S. Department of Energy. The plasma volume is $30 \mathrm{~m}^{3}$ with a major radius of $1.67 \mathrm{~m}$ and a minor radius of 0.67 meters. The experiment is a pulsed device, with an experiment lasting up to 10 seconds.

The Advanced Divertor Program for DIII-D was launched in 1989 with the experimental objectives to study several proposed concepts for density control, enhancement of plasma performance, and current drive. The first phase of the program was the installation of a toroidally continuous ring electrode biasable to $600 \mathrm{~V}$ with $20 \mathrm{kA}$, and a toroidal gas baffle creating a pumping plenum in the lower outer corner of the vacuum chamber (Fig. 1). Results for the first phase were promising. ${ }^{1}$ Large gas pressures were built up under the gas baffle demonstrating particles being collected and not recycled back into the core plasma.

The second phase of the Advanced Divertor is installation of a toroidally continuous cryocondensation pump. This pump provides active pumping of the divertor and will be installed under the toroidal gas baffle. The pumping is achieved by cooling a surface to $4 \mathrm{~K}$ using liquid helium. Particles condense on the heliumcooled surface, preventing them from recycling back into the plasm during the experiment. The particles are then desorbed from the helium-cooled surface after the experimental pulse by heating the helium surface above the freexing point of the particles. The pump will exable scientists to study plasma exhaust and density control by divertor pumping and it is expected to provide low density plasma for if current drive. The cryocondensation pump is presently being built and will be installed in the fall of 1992.

In DIII-D experiments, an abrupt rise in plasma density is typically observed during the transition to $\mathrm{H}$-mode. A gradual rise in density is also seen during long discharges. If the rise in density during this transition can be controlled, better confinement is expected. This is one goal for installing active pumping for the divertor. Active pumping of the divertor is also desirable to compensate for fueling during long plasma discharges. The only other pumping mechanism 


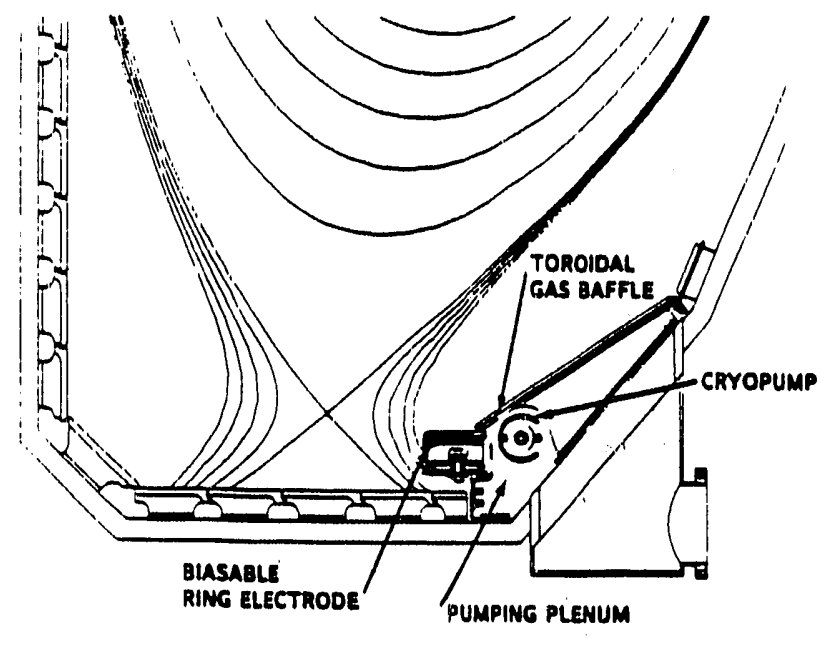

Fig. 1. Advanced Divertor in DIII-D

present is caused by the graphite tiles absorbing particles, but this pumping action saturates as experimental discharges grow longer. Impurity control is another goal of active pumping. If not collected, impurities eventually migrate back into the core plasma and radiate energy from the core, thereby reducing the stored energy of the plasma. Active pumping of the divertor should reduce the impurities recycling back into the plamma

The minimum external fueling rate for DIII-D considered for the pump design in 20 torr liters/second corresponding to $15 \mathrm{MW}$ of injected neutral beam power. To control density during a plama discharge, the pump must be capable of a removal rate of at least this fueling rate. Calculations show that with a pressure build up under the baffle of 0.4 mtorr and a pumping speed of $50,000 \mathrm{l} / \mathrm{s}$, the pump will have a removal rate of 20 torr/ l-sec. ${ }^{2}$ Recent experiments have shown the pressure under the baffle to be as high an 16 mtorr, ${ }^{1}$ so the removal rate of the pump will be much larger.

\section{DESIGN}

A cross section of the pump and its location in the pumping plenum is shown in Fig. 2. The pump is comprised of a series of concentric Inconel 625 tubes cut and assembled together. The pumping surface consists of a $10 \mathrm{~m}$ long, $25 \mathrm{~mm}$ diameter Inconel tube with liquid belium flowing inside. It provides approximately $1 \mathrm{~m}^{2}$ of pumping surface. Surrounding the pumping surface are liquid nitrogen-cooled shields which limit the steady-state heat load on the belium system to less than $10 \mathrm{~W}$. Surrounding the nitrogen-cooled surfacen is a radiation/particle shield to prevent energetic divertor particles from releasing water previously condensed on liquid-nitrogen surfaces. The aperture to the pump is created by cutting windows in the radiation/particle and outer nitrogen shields. The inner nitrogen shield

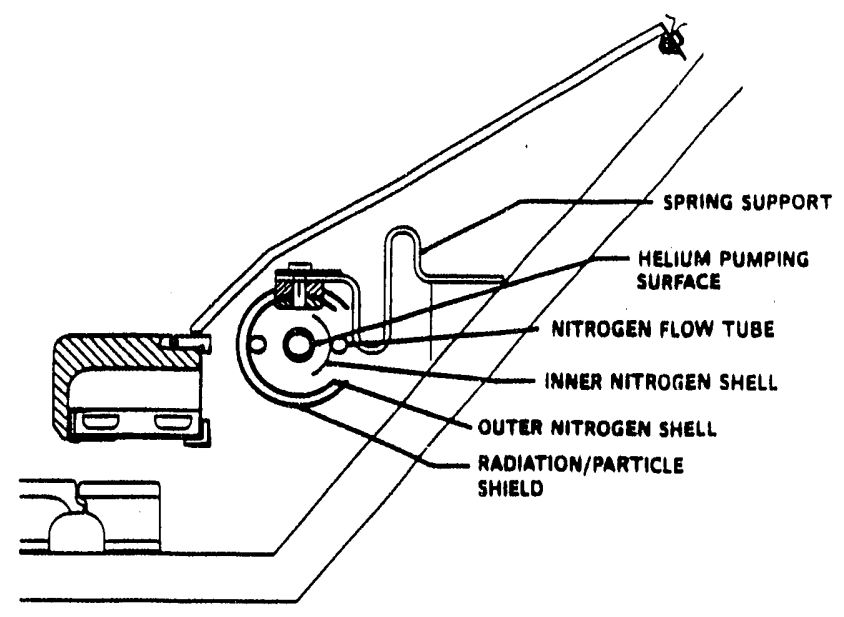

Fig. 2. Cryopump components

provides shieiding to the helium tube from incoming energetic particles. All particles entering the pump must bounce off a nitrogen-cooled surface at least twice before hitting the helium surface. The nitrogen-cooled surfaces are coated with an emissivity enhancing coating to absorb most of the incoming photons.

Glow discharge cleaning is used between shots on DIII-D to clean the walls and desorb oxygen from the graphite tiles to enable better plasma conditions. During conditioning, helium pressures up to 2 mtorr are present for about 300 seconds. This gas pressure creates a large conductive heat load through the gas to the liquid helium pumping surface and the liquid helium flow becomes unstable. Hence, the helium flow will be shut off between shots and the helium panel allowed to warm up. This requires that the helium panel be capable of rapid cool down in less than 5 minutes to be ready for the next planes shot. This regeneration of the helium surface between shots limits the deuterium frost build up on the pump. The helium and nitrogen surface will warm up to $120 \mathrm{~K}$ during glow discharge cleaning. The liquid nitrogen components are designed to cool down in less than $30 \mathrm{~min}$ from $300 \mathrm{~K}$, and the helium surface will chill down from $300 \mathrm{~K}$ to $4 \mathrm{~K}$ in $4.5 \mathrm{~min}$ once the nitrogen shields are cooled.

The flow of the liquid belium is in the forced flow regime and enters the pump as saturated liquid and exits as two-phase helium. The mass flow rate is designed to be $4 \mathrm{gm} / \mathrm{s}$ at $116 \mathrm{kPa}$. By minimizing the amount of gaseous helium and maintaining bubble flow, flow instability is eliminated as a concern. A complete thermal analysis of the system bas been completed. Table I shows a summary of the thermal parameters and limits for the pump. The flow stability has been tested at several heat loads. ${ }^{3}$ Other thermal design considerations for the pump were operation of the machine 
TABLE I

Cryopump Thermal Design Summary

\begin{tabular}{ll}
\hline $\begin{array}{l}\text { Heat loads } \\
\text { Steady-state radiation and conduction }\end{array}$ & $1000 \mathrm{~W}$ \\
to nitrogen shields & \\
Steady-state radiation and conduction & $10 \mathrm{~W}$ \\
to helium panel & $20 \mathrm{~W}$ \\
$\begin{array}{l}\text { Particle load to helium panel } \\
\text { Resistive heating in belium panel }\end{array}$ & $170 \mathrm{~J}$ \\
& \\
$\begin{array}{l}\text { Heat load limits for pump } \\
\text { Hydrogen pumping }(4.6 \mathrm{~K})\end{array}$ & $20 \mathrm{~W}, 10 \mathrm{~s}$ \\
\begin{tabular}{l} 
Deuterium pumping $(6.3 \mathrm{~K})$ \\
\hline
\end{tabular} & $300 \mathrm{~W}, 10 \mathrm{~s}$ \\
\hline
\end{tabular}

with warm pump (no pumping experiments), response of the pump to machine bakeout, and thermal loads on the pump due to fault conditions.

The flow of the liquid helium in the pump will be single pass and the nitrogen flow will be two paes (Fig. 3). The cryogens are fed into the vessel through a single feedthrough. The feedthrough is electrically isolated from the vessel to prevent eddy or disruption induced currents from flowing across the toroidal field, creating large electro-magnetic loads on the feeds. A description of the cryogenic system supporting opera. tion of the pump can be found in Ref. 4 .

The structure of the pump is a series of concentric tubes forming a toroidally continuous ring. The toroidally continuous structure was chosen, after detailed evaluation, over breaking the pump into segments either electrically or mechanically. The primary design issue was the voltage poteutials developed between the vessel wall and the purnp. These voltages could reach $300 \mathrm{~V}$ and with ionized gas existing in the pumping plenum, breakdown between the vessel wall and the pump could result. The flow of current in the pump

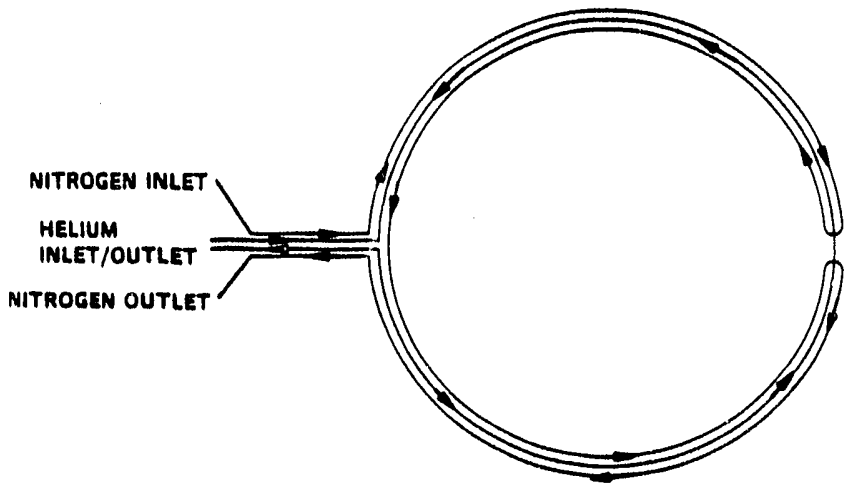

Fig. 3. Plan view of flow pattern of cryogens in pump causes large electromagnetic forces on the pump. The pump system could be designed to carry these loads, but the resulting arc could damage a fluid carrying tube. The main benefits of the pump being toroidally continuous are lowering the voltage potential to less than 50 volts and the risk of arcing is reduced to an acceptable level. Large currents up to $31 \mathrm{kA}$ in the nitrogen shell and $2.9 \mathrm{kA}$ in the helium panel, are induced in the pump during disruptions but the continuous stincture enables the reaction of large radial loads to be carried in hoop. Current is also driven in the pump during plasma rampup and flat top. Analysis shows that the cryopump is capable of operating with the resistive heat load, a total of $185 \mathrm{~J}$ on the helium panel, from this current. The effect of additional resistive heating on the nitrogen shell was also considered. Both the nitrogen and helium shells are electrically and mechanically toroidally continuous and can carry radial loads in hoop streas. The rertical electromagnetic loads in the helium are transmitted by supports to the nitrogen shell and the vertical loads on the nitrogen shell are reacted back to the vessel wall. The helium and nitrogen shields are fabricated in $120^{\circ}$ sections, which are welded together during installation inside the vacuum vessel. There are 24 radiation/particle shello supported from the nitrogen shell. These are slid into place before the welding of the nitrogen shells in the vessel.

The nitrogen shell is supported back to the vacuum vessel wall. The support is designed to allow for the thermal contraction of the system at cryogenic temperatures while the vessel is at $25^{\circ} \mathrm{C}$. The pump changes in radius approximately $0.5 \mathrm{~cm}$ from $25^{\circ} \mathrm{C}$ to $-190^{\circ} \mathrm{C}$. The natural frequency of the support system is designed such that the pump moves with the vessel floor during disruptions. The supports are also designed to attenuate the impulse loads induced on the pump components during disruptions.

The liquid helium tubes are supported of the inner nitrogen shell by a pair of conically wound com. pression springs every 15 degrees (Fig. 4). The springs provide a long heat leak path with all supports summing to a conductive heat load of less than $1.0 \mathrm{~W}$ to the belium. Electrical insulation between the belium and nitrogen systems is provided by two alumina rings per support. The alumina rings are designed to allow the helium tube to slide with respect to the nitrogen shield, thus taking up the differential thermal expansion. The lateral stiffness of the spring supports react the vertical electromagnetic loads on the helium tubes.

The radiation/particle shield is supported from the liquid nitrogen shield by alumina buttons. The buttons are located in sets of three, and there are two sets per $15^{\circ}$ section of the radiation/particle shield. The buttons allow for sliding between the nitrogen shell and the radiation/particle shield, but are kept centered by the nitrogen shell support back to the vessel wall. 


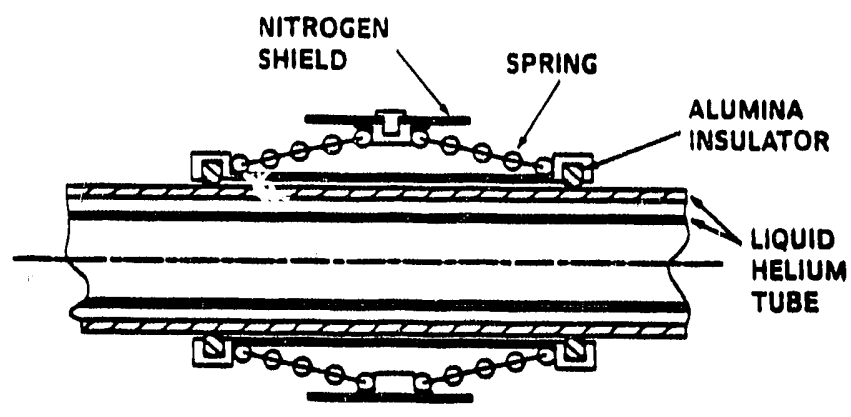

Fig. 4. Low heat leak liquid belium support

\section{MANUFACTURE AND ASSEMBLY}

Different methods of manufacturing the pump were studied to limit the distortion of the components and give stresa-free parts. Inconel 625 tubes were taken and rolled to the appropriate radius. The rolled sections were annealed in a vacuum furnace for stress relief. Laser cutting was chosen over either torch cutting or traditional machining to form the windows in the side of the tube for the pumping aperture.

The liquid nitrogen flow tubes are attached to their shells by a series of $25 \mathrm{~mm}$ long plug welds spaced every $50 \mathrm{~mm}$. Both nitrogen shells were originally rolled to a larger radius than nominal to allow for shrintage during welding. The inside of the outer nitrogen shell is plasma sprayed with a $13 \%$ titanium dioxide $-87 \%$ aluminum axide coating to enhance exoistivity and to reduce the heat load on the helium tribe. The measured coating emissivity is greater than 0.75 at a 10.6 micrometer wavelength. The outer surface of the inner nitrogen shell also has the coating.

The outer nitrogen shell has copper stripes flame sprayed on the outside to enhance aximuthal thermal conductance. This is needed to keep a maximum surface temperature of $110 \mathrm{~K}$ on the nitrogen shell. The stripes are $25 \mathrm{~mm}$ wide,spaced every $50 \mathrm{~mm}$ along the length of the pump. The copper is not toroidally continuous in order to keep the electrical resistance high and minimize the electromagnetic forces on the pump. The stripes coincide with the plug welds to maximize the thermal conductance.
At the four locations for the electric and water feeds of the Advanced Divertor ring electrode, the cross section of the pump is modified to give room for the electrical insulation of these feeds. This also reduces the pump aperture by half for about $20 \%$ of the pump toroidal circumference.

The pump is built up on a tooling plate in $90^{\circ}$ sectors. The belium line is installed inside the inner nitrogen shell and the inner nitrogen shell is welded inside the outer nitrogen shell. The raciation/particle shields are slid over the nitrogen shield into place. A practice installation is then performed in the staging ares to verify access to all welds. The three pump sector assemblies are then brought into the vessel, and welded together and leak checked.

A prototype sector of the pump was built to verify the manufacturing processes and assembly sequence prior to the production of the final pump. Installation of pump is planned for the end of 1992.

\section{ACKNOWLEDGMENT}

This work was sponsored by the U.S. Department of Energy under Contract No. DE-AC03-89ER51114.

\section{REFERENCES}

1 M. A. MAHDAVI, M. SCHAFFER, P. ANDERSON, C. BAXI, et al., Plasma Physics and Controlled Nuciear Fusion Research 1990, (IAEA, Vienna, 1991) p. 335.

2 M. M. MENON, P. M. ANDERSON, C. B. BAXI, A. LANGHORN, et al., "Particle Exhaust Scheme Using an In-Vessel Cryocondensation Pump," General Atomics Report GA-A20618, submitted to Fusion Technology.

3 C. B. BAXI, P. ANDERSON, A. LANGHORN, K. SCHAUBEL, and J. SMITH, "Thermal Design, Analysis and Experimental Verification for a DIII-D Cryogenic Pump," in Proceedings 2nd Intnl. Symp. on Fusion Nuclear Technology, June 2-7, 1991, Karisruhe, Germany.

4 K. M. SCHAUBEL, C. B. BAXI, G. L. CAMPBELL, A. M. GOOTGELD, et al., "Design of the Advanced Divertor Pump Cryogenic System for DIII- $D,{ }^{n}$ in Proceedings of the 14th Symp. on Fusion Engineering, September 30-October 3, 1991, San Diego, California to be published. 

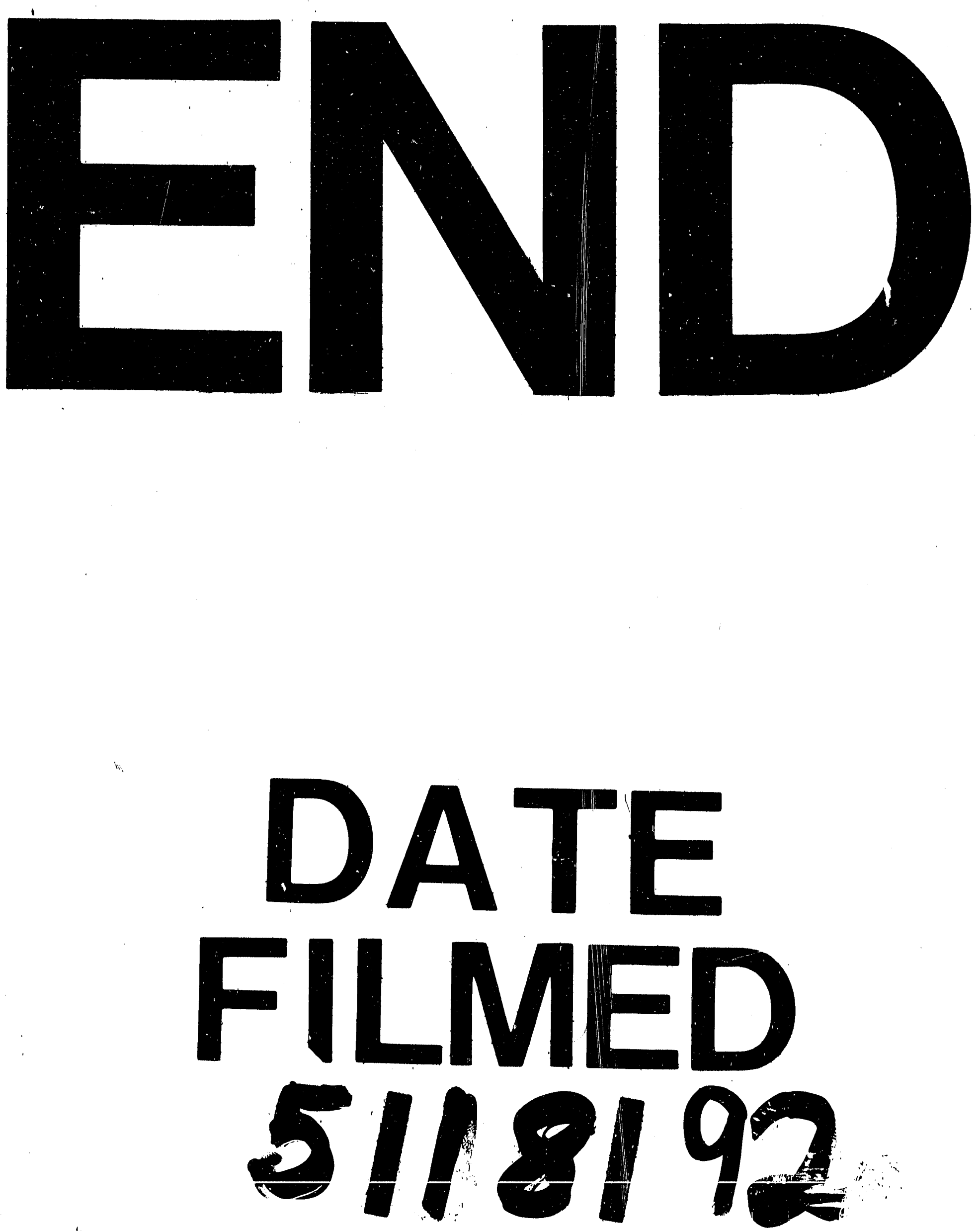


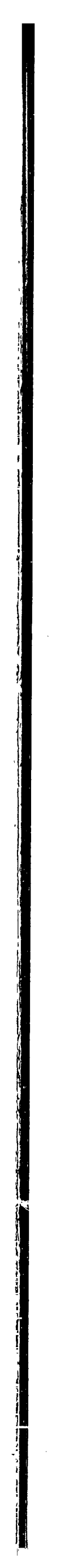

